\title{
Associations of Early Marriage and Early Childbearing with Anemia Among Adolescent Girls in Ethiopia: A Multilevel Analysis of Nationwide Survey
}

Fentanesh Nibret Tiruneh

Bahir Dar University Institute of Technology

Mesfin Wogayehu Tenagashaw

Bahir Dar University Institute of Technology

Degnet Teferi Asres

Bahir Dar University Institute of Technology

Hirut Assaye Cherie ( $\sim$ hirutas2000@gmail.com )

Bahir Dar University Institute of Technology https://orcid.org/0000-0003-3560-4552

\section{Research}

Keywords: Anemia, adolescents, early marriage, early childbearing, community-level, individual-level

Posted Date: December 2nd, 2020

DOI: https://doi.org/10.21203/rs.3.rs-117777/v1

License: (c) (1) This work is licensed under a Creative Commons Attribution 4.0 International License.

Read Full License 


\section{Abstract}

Background: Early marriage and early childbearing are common practices in Ethiopia. Girls who got married and give birth at a very young age are more likely to experience several health problems including anemia among others. However, the effects of early marriage and early childbearing on anemia status of adolescent girls have not been quantified in previous studies. In this study, we assessed whether early marriage and early childbearing measured at both individual and community levels are associated with adolescent anemia.

Methods: We analyzed data from the 2016 demographic and health survey of Ethiopia. Our study concentrated on 3,172 late female adolescents (15-19 years). For bivariate analysis, we used the chisquared test and spearman correlation coefficients. The relationship between early marriage and childbearing with anemia was evaluated using multilevel binary logistic regression models while controlling other determinants.

Results: Overall prevalence of anemia among female adolescents was 23.8 (95\% Cl; 22.3-25.2). Our multivariable multilevel analysis showed that individual-level marital status ( $\mathrm{AOR}=1.53,95 \% \mathrm{Cl}=1.06$ 2.02) and community-level childbearing status ( $A O R=2.80,95 \% \mathrm{Cl} 1.25-6.29)$ were positively associated with anemia among female adolescents.

Conclusion: Our findings show that the consequences of early marriage and early childbearing on adolescent anemia are significant. There is a need to avoid early marriage and childbearing in Ethiopia to improve the health status of adolescent girls.

\section{Background}

Adolescence has been described as the period in life when an individual is no longer a child, but not yet an adult. WHO defines 'Adolescents' as individuals in the 10-19 years age group (1). Furthermore adolscents are further classified into early and late age groups of 10-14 and 15-19 years, respectively(2). There are more than 1.1 billion adolescents worldwide; and approximately $85 \%$ of them live in developing countries(3).

Adolescents are nutritionally vulnerable groups due to the rapid growth and development which occurs at this age. Being at their growth spurt, their dietary needs are high and this makes them to be susceptible to anemia and other micronutrient deficiencies(4).The risk of anemia is greater in females adolescents than males (5). Increased iron requirements, excessive menstrual losses and nutritional deprivation aggravate and worsen pre-existing anemia and its adverse effects among females (6). Studies showed that compared to early teens, late female adolescents are more likely to have anemia (7).

Early marriage (marriage before the age of 18) is associated with many social, physical, and health problems and it is common in many developing countries(8). Women who marry early tend to have less schooling and begin earlier childbearing and care, and have less household decision-making control 
including their health. In addition, domestic abuse is much more likely to happen to them (9). Early marriage is common in Ethiopia, with 40 percent of women age 20-24 first married or in a union before age of 18 . Girls who got married at a very young age are more likely to experience several health problems including anemia, depression and anxiety $(10,11)$. Moreover, women who are engaged in marriage at young ages have much lower, satisfaction with life, self-esteem, and perceptions of gender equality which further affects their health and health related behaviors (12).

Early pregnancy is a serious public health concern due to its potential impact on maternal and child health. Adolescent pregnancy raises the risk of several health complications such as anemia, hypertension caused by pregnancy, preterm labor, maternal mortality, perinatal and neonatal mortality, and low birth weight $(13,14)$. Childbearing during adolescence is also observed to inhibit young girls' post-menarcheal linear and significant development during a potential window of opportunity for catchup development in an undernourished population.In addition, pregnancy and lactation at early gynecological age contribute to the depletion of micronutrients like iron and increase the susceptibility of young mothers to anemia. When adolescents reach pregnancy with low nutritional reserves, this condition is exacerbated (15). Furthermore early marriage and early childbearing affect adolescent nutritional status by lowering their educational attainment and work status which leads to lower-income, low autonomy, and high fertility which together affect nutritional purchasing power, nutritional intake behavior and other outcomes $(16,17)$. Therefore, preventing early marriage and early childbearing not only improves women's and children's health but also help to reduce poverty and improve a country's socio-economic status (18).

The effects of early marriage and early childbirth on adolescent anemia have not been quantified in Ethiopia. Moreover, multilevel analysis was rarely used to investigate community-based clustering of anemia. Community constitutes a key determinant of socioeconomic disparities in health including anemia status, as they shape individual opportunities and expose residents to multiple risks and resources over the life course.Therefore, our study aimed to fill this gap by analyzing the association between early marriage and early childbearing at both individual and community-level with anemia among late female adolescents in Ethiopia. We hypothesized those adolescents who have married and given birth at early age are at higher odds of having anemia than their counterparts.

\section{Methods}

\section{Data source}

We used data sourced from the 2016 Ethiopia Demographic and Health Survey (EDHS) for the analysis. The EDHS used a nationally representative sample and a stratified two-stage cluster sampling design. The sampling design involved randomly selecting communities (clusters) at the first stage and households at the second stage. The sample comprised 645 communities (clusters) in the first stage and 18,008 households in the second stage. In total, 15,683 women age 15-49 years were interviewed. The overall response rate was $95 \%$. Anemia testing was performed after getting consent from the 
participants. Among reproductive-age women, 3,494 were adolescents (age 15-19). About 195 adolescents refused to be tested for their anemia status and 127 adolescents were not present at home during blood collection. Therefore, our analysis was limited to 3,172 female adolescents age 15-19 years making the response rate $90.7 \%$.

\section{Measurements}

\section{Outcome variables}

Our outcome variable was anemia status among female adolescents. The cut-offs for anemia among women are defined by WHO as follows: mild anemia between 10.0 and 10.9 grams of hemoglobin per deciliter (g/dl); moderate anemia between7.0 to $9.9 \mathrm{~g} / \mathrm{dl}$ and severe anemia less than $7.0 \mathrm{~g} / \mathrm{dl}(19)$. Because of very few numbers of cases in the category of severe anemia in our dataset, we have created two dichotomous variables where " 0 " denotes no anemia and " 1 " any anemia.

\section{Individual-level independent variables}

Individual-level variables included in our analysis were respondents' marital status, religion, educational level, employment status, place of residence, nutritional status, pregnancy status, breastfeeding status, childbearing, use of contraceptive and visiting health facility in the last 12 months.

Wealth index was constructed using data on a household's ownership of selected assets such as television, materials used for constructing the house, etc. Factor scores of household assets were generated through principal component analysis and then standardized and categorized into quintiles (poorer, poor, middle, rich and richer).

\section{Community-level independent variables}

Based on the aggregation of individual responses for each item at the community (cluster) level, we assessed four community-level variables: proportions of female adolescents who had married, had secondary or higher-level education, had ever childbirth and used contraceptives in the community. These variables represented the community norms and social contexts.

\section{Statistical analyses}

All analyses were performed using SAS (version 9.4). We performed a series of bivariate analyses using chi-square tests to examine the association of individual- and community-level characteristics with the outcome variable (anemia). We also calculated Spearman correlation coefficients to analyze the relationship among the community-level characteristics.

We further conducted multilevel multivariable binary regression models by using the "GLIMMIX" command in SAS to analyze the relationships between individual and community level explanatory variables with anemia. 
Assuming that adolescents who are living in the same community to be more similar to each other than individuals from different communities, the multilevel binary logistic regression models were used to adjust the correlated individual responses nested under the same community. We reported Intraclass correlations (ICC) to assess the extent to which community variances were explained in each model.

\section{Model building}

Four models were created. The first model (empty model) included the outcome variable only to check the variance in anemia between communities. The second model (model with only individual-level variables), the third model (model with only community-level variables) and the final multilevel model contains both individual level and community level variables fitted simultaneously with anemia. The fixed effects for the multilevel binary logistic regression model were reported as adjusted odds ratios (AORs) with 95\% confidence intervals $(\mathrm{Cl})$. The random effects were assessed using the intraclass correlation coefficient (ICC). Goodness of fit for each model was assessed using deviation information criterion, while the variance inflation factor and tolerance were used to examine multicollinearity. No multicollinearity problem was observed among the independent variables in the regression models (all tolerance $>0.1$ and all VIF $<10)$

\section{Ethics statement}

The survey protocol, including biomarker collection, was reviewed and approved by the Federal Democratic Republic of Ethiopia Ministry of Innovation and Technology and the Institutional Review Board of ICF International. Informed consent was obtained at the beginning of data collection and anemia testing was obtained from their caretakers (parent/responsible adult). The authors sought consent from the DHS program to use the data.

\section{Results}

Table 1 shows individual and community-level characteristics of female adolescents participated in our study.About 727(23\%) adolescents were married. About 2067 (65\%) of them live in rural areas. Regarding religion, 1310 (41.3\%) of them were Orthodox Christians followed by 1255(39.5\%) Muslims. Around $331(10.4 \%)$ of adolescents had early childbearing stories; about $200(6.3 \%)$ of respondents used contraceptives and 1005 (31.7\%) of adolescents were underweight. 
Table 1

Individual and community-level characteristics of female adolescents in Ethiopia $(n=3,172)$

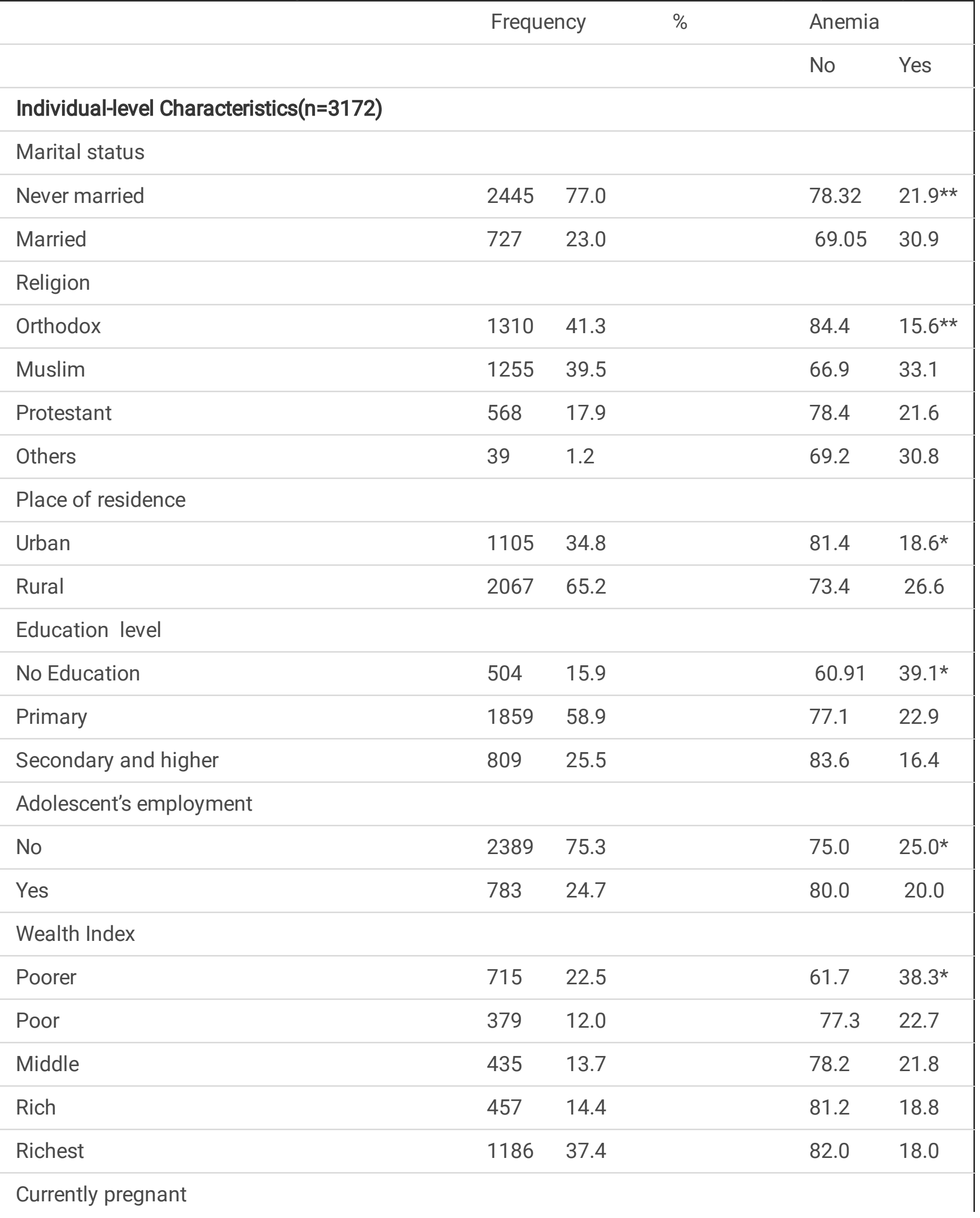




\begin{tabular}{|c|c|c|c|c|}
\hline No & 3065 & 96.6 & 76.7 & $23.3^{*}$ \\
\hline Yes & 107 & 3.4 & 61.9 & 38.3 \\
\hline \multicolumn{5}{|l|}{ Currently breastfeeding } \\
\hline No & 2944 & 92.8 & 76.8 & $23.2^{\star}$ \\
\hline Yes & 228 & 7.2 & 68.4 & 31.6 \\
\hline \multicolumn{5}{|l|}{ Early childbearing } \\
\hline No & 2841 & 89.6 & 77.5 & $22.5^{\star \star}$ \\
\hline Yes & 331 & 10.4 & 65.3 & 34.7 \\
\hline \multicolumn{5}{|l|}{ Current use of contraceptive } \\
\hline No & 2972 & 93.7 & 75.8 & $24.2^{\star}$ \\
\hline Yes & 200 & 6.3 & 82.5 & 17.5 \\
\hline \multicolumn{5}{|l|}{ Nutritional status (BMI) } \\
\hline <18.5(underweight) & 1005 & 31.7 & 71.1 & $28.9 * *$ \\
\hline 18.5-24.9 (normal weight) & 2023 & 63.8 & 78.8 & 21.2 \\
\hline$\geq 25$ (overweight) & 144 & 4.6 & 75.0 & 25.0 \\
\hline \multicolumn{5}{|c|}{ Visiting health facility in the last 12 months } \\
\hline No & 2338 & 73.7 & 76.3 & 23.7 \\
\hline Yes & 834 & 26.3 & 75.9 & 24.1 \\
\hline \multicolumn{5}{|c|}{ Community-level characteristics(n=645) } \\
\hline \multicolumn{5}{|c|}{$\%$ of married adolescent's in the community } \\
\hline Low & 396 & 61.4 & 79.1 & $20.9 * \star$ \\
\hline High & 249 & 38.6 & 71.9 & 28.1 \\
\hline \multicolumn{5}{|c|}{$\begin{array}{l}\% \text { of adolescents who had childbearing in the } \\
\text { community }\end{array}$} \\
\hline Low & 418 & 64.8 & 78.6 & $21.4^{\star *}$ \\
\hline High & 227 & 35.3 & 72.5 & 27.5 \\
\hline \multicolumn{5}{|c|}{$\begin{array}{l}\% \text { of adolescents with secondary and higher } \\
\text { education in the community }\end{array}$} \\
\hline Low & 286 & 44.3 & 73.2 & $26.8^{\star \star}$ \\
\hline High & 359 & 55.7 & 78.8 & 21.1 \\
\hline
\end{tabular}


$\%$ of adolescents who use contraceptive in the community

Low

High

Outcome variable (Anemia)

No anemia

Anemia

${ }^{* *} \mathrm{P}<0.001, \mathrm{p}<0.05 ;$ Data source 2016, EDHS
$2417 \quad 76.2$

$755 \quad 23.8(95 \% \mathrm{Cl} ; 22.3-$

25.2)

The prevalence of anemia among female adolescents was $23.8 \%(95 \% \mathrm{Cl} ; 22.3-25.2)$. Our chi-square test showed that almost all variables had significant associations with anemia both at 0.01 and 0.05 significant levels.

Among communities, an average of $58.8 \%$ t adolescents had secondary and higher education. Overall, $26.1 \%$ of the respondents were married; $11.2 \%$ had history of early childbearing and $8.4 \%$ used contraceptives (Table 2).

Table 2

Pearson Correlation matrix among community-level characteristics $(n=645)$.

\begin{tabular}{|llllll|}
\hline & $\begin{array}{l}\text { Mean } \\
\text { (standard } \\
\text { deviation) }\end{array}$ & A & B & C & D \\
\hline $\begin{array}{l}\text { A. Percentage of adolescents with secondary } \\
\text { and higher education }\end{array}$ & $58.8(30.9)$ & 1.00 & & & \\
\hline B. Percentage of married adolescents & $26.1(25.4)$ & -0.02 & 1.00 & \\
\hline $\begin{array}{l}\text { C. Percentage of adolescents who give } \\
\text { childbirth }\end{array}$ & $11.2(10.9)$ & -0.04 & $0.41^{*}$ & 1.00 & \\
\hline $\begin{array}{l}\text { D. Percentage of adolescents who used } \\
\text { contraceptive }\end{array}$ & $8.4(9.7)$ & 0.075 & $0.34^{*}$ & $0.19^{*}$ & 1.00 \\
\hline$* P<0.05$ & & & & & \\
\hline
\end{tabular}

Table 3 depicts the results of our multilevel analysis. The empty model indicated that $29 \%$ of the variation of anemia among female adolescents was attributable to different factors that operate at the community level $(I C C=0.29 ; \mathrm{P}<0.001)$. 
Table 3

Multilevel logistic regression

$\begin{array}{lllll}\text { Variables } & \begin{array}{l}\text { Empty } \\ \text { model }\end{array} & \begin{array}{l}\text { Model with } \\ \text { individual } \\ \text { level }\end{array} & \begin{array}{l}\text { Model with } \\ \text { the } \\ \text { community } \\ \text { level }\end{array} & \begin{array}{l}\text { Model with individual } \\ \text { and community-level } \\ \text { variables }\end{array} \\ & \begin{array}{l}\text { variables } \\ \text { AOR(95\% }\end{array} & \begin{array}{l}\text { variable } \\ \text { AOR(95\% }(95 \% \mathrm{Cl})\end{array} & \text { AOR })\end{array}$

Individual -level characteristics(n

$=3,172$ )

Marital status

Never married

Ref.

Ref.

Married

1.54(1.07-

$2.22) *$

$1.53(1.06-2.20) *$

Religion

Orthodox

Ref.

Ref.

Muslim

2.85(1.79-

4.52)*

$2.51(1.56-4.01) *$

Protestant

$1.40(0.84-$

2.31)

$1.36(0.81-2.25)$

Others

7.68(2.59-

$21.85)^{\star}$

7.08(0.88-19.02)

Place of residence

Urban

Ref.

Ref.

Rural

$0.86(0.44-$

1.81)

1.03(0.46-2.27)

Wealth Index

Poorer

Ref.

Ref.

Poor

0.87(0.64-

1.19)

Middle

$0.92(0.66-$

1.27)

Rich

$0.79(0.56-$

1.12)

$0.90(0.66-1.22)$

$0.95(0.69-1.32)$

$0.84(0.59-1.18)$

AOR: Adjusted odds ratio, Cl: confidence interval, DIC: deviation information criterion, ICC: intraclass correlation coefficient, AlC: Akaike information criterion. * Significant at P-value $<0.05$ 


\begin{tabular}{|c|c|c|c|c|}
\hline Variables & $\begin{array}{l}\text { Empty } \\
\text { model }\end{array}$ & $\begin{array}{l}\text { Model with } \\
\text { individual } \\
\text { level } \\
\text { variables } \\
\text { AOR(95\%Cl) }\end{array}$ & $\begin{array}{l}\text { Model with } \\
\text { the } \\
\text { community } \\
\text { level } \\
\text { variable } \\
\text { AOR }(95 \% \mathrm{Cl})\end{array}$ & $\begin{array}{l}\text { Model with individual } \\
\text { and community-level } \\
\text { variables } \\
\text { AOR( } 95 \% \mathrm{Cl})\end{array}$ \\
\hline Richest & & $\begin{array}{l}0.87(0.57- \\
0.98)^{\star}\end{array}$ & & $0.91(0.60-1.39)$ \\
\hline \multicolumn{5}{|l|}{ Education level } \\
\hline No Education & & Ref. & & Ref. \\
\hline Primary & & $\begin{array}{l}0.45(0.34- \\
0.65)^{*}\end{array}$ & & $0.48(0.33-0.71) *$ \\
\hline Secondary and Higher & & $\begin{array}{l}0.21(0.13- \\
0.34)^{\star}\end{array}$ & & $0.22(0.13-0.35) *$ \\
\hline \multicolumn{5}{|l|}{ Employment } \\
\hline No & & Ref. & & Ref. \\
\hline Yes & & $\begin{array}{l}0.85(0.72- \\
0.99)^{*}\end{array}$ & & $0.85(0.72-1.01)$ \\
\hline \multicolumn{5}{|l|}{ Currently pregnant } \\
\hline No & & Ref. & & Ref. \\
\hline Yes & & $\begin{array}{l}1.03(0.76- \\
1.40)\end{array}$ & & $1.03(0.76-1.40)$ \\
\hline \multicolumn{5}{|l|}{ Currently breastfeeding } \\
\hline No & & Ref. & & \\
\hline Yes & & $\begin{array}{l}0.89(0.74- \\
0.97)^{*}\end{array}$ & & $0.89(0.74-1.08)$ \\
\hline \multicolumn{5}{|l|}{ Early childbearing } \\
\hline No & & Ref. & & Ref. \\
\hline Yes & & $\begin{array}{l}1.22(0.77- \\
1.95)\end{array}$ & & $1.12(0.70-1.80)$ \\
\hline \multicolumn{5}{|c|}{ Current use of contraceptive } \\
\hline No & & Ref. & & \\
\hline Yes & & $\begin{array}{l}0.47(0.26- \\
0.85)^{\star}\end{array}$ & & $0.57(0.32-1.04)$ \\
\hline
\end{tabular}




\begin{tabular}{|c|c|c|c|c|}
\hline Variables & $\begin{array}{l}\text { Empty } \\
\text { model }\end{array}$ & $\begin{array}{l}\text { Model with } \\
\text { individual } \\
\text { level } \\
\text { variables } \\
\text { AOR(95\%Cl) }\end{array}$ & $\begin{array}{l}\text { Model with } \\
\text { the } \\
\text { community } \\
\text { level } \\
\text { variable } \\
\text { AOR(95\%Cl) }\end{array}$ & $\begin{array}{l}\text { Model with individual } \\
\text { and community-level } \\
\text { variables } \\
\text { AOR }(95 \% \mathrm{Cl})\end{array}$ \\
\hline \multicolumn{5}{|c|}{ Nutritional status (BMI) } \\
\hline$<18.5$ & & Ref. & & Ref. \\
\hline $18.5-24.9$ & & $\begin{array}{l}0.56(0.44- \\
0.33)^{*}\end{array}$ & & $0.58(0.45-0.75) *$ \\
\hline$\geq 25$ & & $\begin{array}{l}0.38(0.21- \\
0.69) *\end{array}$ & & $0.43(0.32 .0 .54)^{\star}$ \\
\hline \multicolumn{5}{|c|}{$\begin{array}{l}\text { Visiting health facility in the last } \\
12 \text { months }\end{array}$} \\
\hline No & & Ref. & & Ref. \\
\hline Yes & & $\begin{array}{l}1.15(0.91- \\
1.33)\end{array}$ & & $1.10(0.94-1.30)$ \\
\hline \multicolumn{5}{|c|}{$\begin{array}{l}\text { Community-level } \\
\text { characteristics }(n=645)\end{array}$} \\
\hline \multicolumn{5}{|c|}{$\begin{array}{l}\% \text { of adolescents with secondary } \\
\text { and higher education in the } \\
\text { community }\end{array}$} \\
\hline Low & & & Ref. & Ref. \\
\hline High & & & $\begin{array}{l}0.64(0.33- \\
1.23)\end{array}$ & $0.61(0.31-1.19)$ \\
\hline \multicolumn{5}{|c|}{$\begin{array}{l}\% \text { Percentage of married } \\
\text { adolescents in the community }\end{array}$} \\
\hline Low & & & Ref. & Ref. \\
\hline High & & & $\begin{array}{l}1.52(0.68- \\
3.38)\end{array}$ & $0.79(0.35-1.77)$ \\
\hline \multicolumn{5}{|c|}{$\begin{array}{l}\% \text { of adolescents who were } \\
\text { childbearing in the community }\end{array}$} \\
\hline Low & & & Ref. & Ref. \\
\hline High & & & $\begin{array}{l}4.12(1.83- \\
5.24)^{*}\end{array}$ & $2.8(1.25-6.29)^{*}$ \\
\hline
\end{tabular}

AOR: Adjusted odds ratio, Cl: confidence interval, DIC: deviation information criterion, ICC: intraclass correlation coefficient, AlC: Akaike information criterion. * Significant at P-value $<0.05$ 


\begin{tabular}{|c|c|c|c|c|}
\hline Variables & $\begin{array}{l}\text { Empty } \\
\text { model }\end{array}$ & $\begin{array}{l}\text { Model with } \\
\text { individual } \\
\text { level } \\
\text { variables } \\
\text { AOR(95\%Cl) }\end{array}$ & $\begin{array}{l}\text { Model with } \\
\text { the } \\
\text { community } \\
\text { level } \\
\text { variable } \\
\text { AOR(95\%Cl) }\end{array}$ & $\begin{array}{l}\text { Model with individual } \\
\text { and community-level } \\
\text { variables } \\
\text { AOR(95\% })\end{array}$ \\
\hline \multicolumn{5}{|c|}{$\begin{array}{l}\% \text { of adolescents who used } \\
\text { contraceptive in the community }\end{array}$} \\
\hline Low & & & Ref. & Ref. \\
\hline High & & & $\begin{array}{l}0.16(0.07- \\
0.34)^{\star}\end{array}$ & $0.31(0.14-0.69) *$ \\
\hline \multicolumn{5}{|l|}{ Measures of variation } \\
\hline ICC & $0.29 *$ & $0.23^{*}$ & $0.25^{\star}$ & $0.21 *$ \\
\hline \multicolumn{5}{|l|}{ Model fit statistics } \\
\hline DIC (-2log likelihood) & 7054.6 & 6919.68 & 7004.63 & 6904.29 \\
\hline
\end{tabular}

The analysis of the outcome variable with individual-level variables revealed that adolescents' marital status, religion, household wealth index, educational level, employment status, breastfeeding status, contraceptive use and nutritional status were significantly associated with anemia. This model showed that $23 \%$ of the variation of anemia among female adolescents was due to differences at the community level $(I C C=0.23 ; P<0.05)$.

In the final model, we put both individual and community-level variables simultaneously and examined their association with anemia. The results showed that married adolescents were 1.53 times ( $A O R=1.53$; $95 \% \mathrm{Cl}: 1.06-2.20)$ more likely to be anemic compared to non-married adolescents. Muslim adolescents were 2.51 times $(A O R=2.51 ; 95 \% \mathrm{Cl}: 1.56-4.01)$ more likely to develop anemia than Orthodox Christians. Adolescents who had primary, secondary and higher education level had 0.48 and 0.22 times ( $A O R=0.48$; $95 \% \mathrm{Cl}: 0.33-0.71$ and $\mathrm{AOR}=0.22 ; 95 \% \mathrm{Cl}: 0.13-0.35$ respectively, ) lower odds of having anemia compared to adolescents who had no formal education. Adolescents who had normal and overweight nutritional status were 0.58 and 0.43 times $(\mathrm{AOR}=0.58 ; 95 \% \mathrm{Cl}: 0.45-0.75$ and $\mathrm{AOR}=0.43 ; 95 \% \mathrm{Cl}$ : $0.32-$ 0.54 ) less likely to be anemic than underweight adolescents. Moreover, female adolescents from communities with a higher proportion of childbearing adolescents were 2.8 times (AOR $=2.80 ; 95 \% \mathrm{Cl}$ : 1.25-6.29) more likely to develop anemia than adolescents from communities with a lower proportion of childbearing adolescents. By contrast, adolescents from communities with a higher proportion of contraceptive user adolescents had 0.69 times $(A O R=0.31 ; 95 \% \mathrm{Cl}: 0.14-0.69)$ lower odds of having 
anemia compared to their counterparts. The ICC in the final model suggests that about $21 \%$ variation in anemia may be attributable to other unobserved community-level factors $(\mathrm{ICC}=0.21 ; \mathrm{P}<0.05)$.

\section{Discussion}

Our study reveals that the overall prevalence of anemia among female adolescents aged between 1519 years was $23.8 \%$. According to $\mathrm{WHO}$, anemia is a moderate public health concern among female adolescents in Ethiopia (20). Our finding is comparable to previous studies conducted in Southern Ethiopia and Northwest Ethiopia $(21,22)$. However, the prevalence is comparatively lower than studies done in Ambo Town, West Shewa, Ethiopia, which reported a prevalence as high as 39\%(23); in Haramaya, Eastern Ethiopia which reported 29\% prevalence among school adolescents(24) and 27\% in southwest rural Ethiopia(25). The potential reason for this discrepancy could be the target population, geographical area, and sample size variations. For instance, the current study was nationwide and included both in school and out of school adolescents, and considered rural, peri- urban and urban areas.

As anticipated,we noted that married adolescents were more likely to be anemic than never married counterparts. A similar finding was also reported in India (26). The possible explanation for this result could be early married adolescents are vulnerable to pregnancy and birth-related bleedings, as well as other complications that may raise the risk of anemia (27). Early marriage and early childbearing also affect adolescent nutritional status indirectly. First, as marriage is often cited as an important factor in dropping out of school and college among adolescents in developing countries including Ethiopia, it has a negative impact on their educational achievement (16). In addition, low levels of education have an effect on employment status and contribute to lower incomes, low autonomy and high fertility, which together affect nutritional purchasing power, nutritional intake behavior and outcomes (17).

Muslim adolescents had higher odds of developing anemia compared to Orthodox Christians. The potential explanation for this finding may be due to religious adherents. The norms and principles of the Muslim religion encourage large family size, early marriage and lesser use of contraceptives compared to Orthodox Christians (26-28).

Our study revealed that adolescent's educational level was inversely associated with anemia. Adolescents who had some kind of formal education had lower odds of having anemia than adolescents who had no formal education. The possible explanation for this finding could be related to early marriage and childbearing as adolescents with at least some secondary schooling are less likely to get married at a very young age than uneducated ones. Furthermore, education is positively associated with contraceptive use which can prevent early childbearing and reducing the risk of anemia (29).

Our study noted that adolescents who had normal and overweight nutritional status were less likely to be anemic compared to underweight adolescents. The result was consistent with reports of previous studies $(30,31)$. Undernourished adolescents have more chance to be deficient in one or more micronutrients which may result in an increased risk of anemia (32). In light of our results, our study recommended that 
national anemia prevention programs should concentrate on promoting safe dietary practices to maintain a healthy $\mathrm{BMI}$ and promote iron supplements to ensure optimal nutrition among adolescents.

The effect of community characteristics on individual health outcomes and behaviors has been reported by prior studies $(33,34)$. Our analysis recognized that unlike individual-level childbearing status, community-level adolescent's childbearing was positively associated with anemia. Our hypothesis is partially supported by this finding. Even after we adjusted for their childbearing status and other individual and group-level characteristics, an adolescent living in a community with a higher percentage of adolescents who had childbearing stories was more likely to have anemia. The potential reason may be related to sociocultural norms as adolescent births are irrefutably related to the cultural and social norms of a society (35). Some social norms such as child / early marriage and early childbearing may adversely affect adolescent health including being anemic. In most African countries including Ethiopia, married adolescents are expected to become pregnant within a year after marriage. As a consequence, Ethiopia has one of the highest teenage births with around 143 per 1000 girls between the ages of $15-19$ falling pregnant (36). Restricted social and decision-making autonomy for female adolescents also impacts health preferences, including the use of contraception for early married adolescents to prevent early childbearing (37).

This study revealed that in addition to community-level adolescents' childbearing status community-level contraceptive use was also associated with adolescent's anemic status. An adolescent living in a community with a higher proportion of contraceptive users had lower odds of having anemia. This could be justified by adolescents who used contraceptive methods prevent complications related to early pregnancy and childbirth, which could eventually reduce the prevalence of anemia due to recurrent blood loss. Another plausible justification might be the use of contraceptives could minimize menstrual bleeding and reduce their susceptibility to anemia $(38,39)$. Furthermore, adolescents who use contraceptives are more likely to be educated and autonomous and will subsequently be aware of their health and health related behavior. A higher concentration of autonomous adolescents in the community can promote the dissemination of information via informal social networks to those with lower autonomous peers (40).

\section{Study Limitations}

There are some possible limitations to this study. First, the use of data obtained from a cross-sectional study makes it difficult to infer causality between independent variables (early marriage and childbirth) and the outcome variable (anemia). Second, we were unable to adjust all confounding factors because this study is based on secondary data analysis. Third, adopting community-based measures by aggregating individual responses to the community level may have increased the probability of misclassification of individuals to inappropriate administratively defined boundaries (clusters) potentially leading to information bias. Despite these limitations, our study used a national representative large sample and therefore, results from the current analysis may be generalized to Ethiopian late female adolescents. 


\section{Conclusion}

Our study demonstrates the importance of considering both individual- and community-level characteristics when investigating the effects early marriage and childbearing on adolescent anemia. This study finding shows that the effects of early marriage and early childbearing on adolescent anemia are very significant. Consequently, there is a need to prevent early marriages and early childbearing in Ethiopia. This will help to improve the socio-economic status of young women, thereby improving their nutritional status.

\section{Abbreviations}

AOR: Adjusted Odd Ratio; BMI: Body mass index; Cl: Confidence Interval;DIC: Deviation Information Criterion; EDHS: Ethiopia Demographic Health Survey; ICC: Intraclass Correlation Coefficient; SAS: Statistical Analysis Software; VIF: variance inflation factor, WHO: World Health Organization

\section{Declarations}

\section{Ethics approval and consent to participate}

The survey procedure, including the selection of biomarkers, was reviewed and approved by the Ministry of Innovation and Technology, the Federal Democratic Republic of Ethiopia and the ICF International Institutional Review Board. Authors have been given permission to use the data on the DHS website through written consent:https://dhsprogram.com/data/dataset/Ethiopia_Standard-DHS_2016.cfm? flag $=0$

\section{Consent for publication}

Not applicable

\section{Availability of data and materials}

Dataset analyzed in the current study is available in https://dhsprogram.com/data/dataset/Ethiopia_Standard-DHS_2016.cfm?flag

\section{Competing interests}

The authors declare that they do not have competing interests.

\section{Funding}

This study did not receive any funding.

\section{Authors' contributions}


FNT designed the study and analyzed the data; FNT and HAC drafted the manuscript; MWT and DTA revised the draft. All authors read and approved the final manuscript.

\section{Acknowledgments}

We acknowledge the MEASURE DHS for the permission to use the EDHS data set for analysis.

\section{References}

1. Assembly UG. Convention on the Rights of the Child. United Nations, Treaty Series. 1989;1577(3).

2. Patton GC, Sawyer SM, Santelli JS, Ross DA, Afifi R, Allen NB, et al. Our future: a Lancet commission on adolescent health and wellbeing. The Lancet. 2016;387(10036):2423-78.

3. organization Wh. Orientation program on adolescent health for health care providers Accessed on October, 2020 ;https://www.who.int/maternal child adolescent/documents/pdfs/9241591269_op_handout.pdf

4. Premalatha T, Valarmathi S, Parameshwari S, Jasmine S, Sundar S, Kalpana S. Prevalence of anemia and its associated factors among adolescent school girls in Chennai, Tamil Nadu, India. Epidemiol an open access journal. 2012;2.

5. Chalise B, Aryal KK, Mehta RK, Dhimal M, Sapkota F, Mehata S, et al. Prevalence and correlates of anemia among adolescents in Nepal: Findings from a nationally representative cross-sectional survey. PloS one. 2018;13(12):e0208878.

6. Rati SA, Jawadagi S. Prevalence of anemia among adolescent girls studying in selected schools. International Journal of Science and Research. 2014;3(8):1237-42.

7. Engidaw MT, Wassie MM, Teferra AS. Anemia and associated factors among adolescent girls living in Aw-Barre refugee camp, Somali regional state, Southeast Ethiopia. PloS one. 2018;13(10):e0205381.

8. Hamed A, Yousef F. Prevalence, health and social hazards, and attitude toward early marriage in evermarried women, Sohag, Upper Egypt. Journal of Egyptian Public Health Association. 2017;92(4):22834.

9. Jensen R, Thornton R. Early female marriage in the developing world. Gender \& Development. 2003;11(2):9-19.

10. Chaturvedi S, Kapil U, Bhanthi T, Gnanasekaran N, Pandey R. Nutritional status of married adolescent girls in rural Rajasthan. The Indian Journal of Pediatrics. 1994;61(6):695-701.

11. Le Strat Y, Dubertret C, Le Foll B. Child marriage in the United States and its association with mental health in women. Pediatrics. 2011;128(3):524-30.

12. Abate MG, Tareke AA. Individual and community level associates of contraceptive use in Ethiopia: a multilevel mixed effects analysis. Archives of Public Health. 2019;77(1):46.

13. Child Health Epidemiology Reference Group Kozuki Naoko Lee Anne C. Katz Joanne jkatz@ jhsph. edu Author disclosures: N. Kozuki AL, J. Katz ncoi. Moderate to severe, but not mild, maternal anemia 
is associated with increased risk of small-for-gestational-age outcomes. The Journal of nutrition. 2012;142(2):358-62.

14. Riu D, Mappaware N, Asmi M, Tansil A. Maternal hemoglobin concentration and birth weight: A report from mother and child tertiary hospital. Enfermería Clínica. 2020;30:92-5.

15. Rah JH, Christian P, Shamim AA, Arju UT, Labrique AB, Rashid M. Pregnancy and lactation hinder growth and nutritional status of adolescent girls in rural Bangladesh. The Journal of nutrition. 2008;138(8):1505-11.

16. Rah J. Adolesent pregnancy, its impact on the growth and nutritional status of young mothers: What does evidence say. Sight Life. 2013;27:37-8.

17. Lenders $\mathrm{CM}, \mathrm{McEl}$ rath TF, Scholl TO. Nutrition in adolescent pregnancy. Current opinion in pediatrics. 2000;12(3):291-6.

18. Kassa GM, Arowojolu AO, Odukogbe A-TA, Yalew AW. Trends and determinants of teenage childbearing in Ethiopia: evidence from the 2000 to 2016 demographic and health surveys. Italian Journal of Pediatrics. 2019;45(1):153.

19. Organization WH. Haemoglobin concentrations for the diagnosis of anaemia and assessment of severity. World Health Organization, 2011.

20. WHO. The global prevalence of anaemia in 2011. Geneva: World Health Organization. 2015.

21. Shaka MF, Wondimagegne YA. Anemia, a moderate public health concern among adolescents in South Ethiopia. PloS one. 2018;13(7):e0191467.

22. Gonete KA, Tariku A, Wami SD, Derso T. Prevalence and associated factors of anemia among adolescent girls attending high schools in Dembia District, Northwest Ethiopia, 2017. Archives of Public Health. 2018;76(1):79.

23. Tura MR, Egata G, Fage SG, Roba KT. Prevalence of Anemia and Its Associated Factors Among Female Adolescents in Ambo Town, West Shewa, Ethiopia. Journal of Blood Medicine. 2020;11:279.

24. Fage SG, Egata G, Dessie Y, Kumsa FA, Mizana BA. Anemia among School Adolescents in Haramaya Town, Eastern Ethiopia: Cross-Sectional Study. Nutrition and metabolic insights. 2020;13:1178638820953131.

25. Regasa RT, Haidar JA. Anemia and its determinant of in-school adolescent girls from rural Ethiopia: a school based cross-sectional study. BMC women's health. 2019;19(1):98.

26. Ghosh S. Exploring socioeconomic vulnerability of anaemia among women in eastern Indian States. Journal of biosocial science. 2009;41(6):763.

27. Townsley DM, editor Hematologic complications of pregnancy. Seminars in hematology; 2013: Elsevier.

28. Rai S. prevalence of anemia and associated factors among pregnant women of itahari submetropolitan city 2018.

29. Singh S, Samara R. Early marriage among women in developing countries. International family planning perspectives. 1996:148-75. 
30. Qin Y, Melse-Boonstra A, Pan X, Yuan B, Dai Y, Zhao J, et al. Anemia in relation to body mass index and waist circumference among Chinese women. Nutrition journal. 2013;12(1):1-3.

31. Ausk KJ, loannou GN. Is obesity associated with anemia of chronic disease? A population-based study. Obesity. 2008;16(10):2356-61.

32. Ghose B, Yaya S, Tang S. Anemia status in relation to body mass index among women of childbearing age in Bangladesh. Asia Pacific Journal of Public Health. 2016;28(7):611-9.

33. Tiruneh FN, Chuang K-Y, Chuang Y-C. Women's autonomy and maternal healthcare service utilization in Ethiopia. BMC health services research. 2017;17(1):718.

34. Ntenda PAM, Chuang K-Y, Tiruneh FN, Chuang Y-C. Multilevel analysis of the effects of individualand community-level factors on childhood Anemia, severe Anemia, and hemoglobin concentration in Malawi. Journal of tropical pediatrics. 2018;64(4):267-78.

35. Wanjohi AM. Social and Cultural Factors Influencing Teenage Pregnancies Among Secondary School Students in Gucha District of Kenya. Available at SSRN 1978889. 2010.

36. Akella D. Socio-Cultural Influences on Teenage Pregnancy and Contemporary Prevention Measures: IGI Global; 2018.

37. Pulerwitz J, Blum R, Cislaghi B, Costenbader E, Harper C, Heise L, et al. Proposing a conceptual framework to address social norms that influence adolescent sexual and reproductive health. The Journal of Adolescent Health. 2019;64(4 Suppl):S7.

38. Miller L, Hughes JP. Continuous combination oral contraceptive pills to eliminate withdrawal bleeding: a randomized trial. Obstetrics \& Gynecology. 2003;101(4):653-61.

39. Haile ZT, Teweldeberhan AK, Chertok IR. Association between oral contraceptive use and markers of iron deficiency in a cross-sectional study of Tanzanian women. International Journal of Gynecology \& Obstetrics. 2016;132(1):50-4.

40. Tiruneh FN, Chuang K-Y, Ntenda PAM, Chuang Y-C. Individual-level and community-level determinants of cervical cancer screening among Kenyan women: a multilevel analysis of a Nationwide survey. BMC women's health. 2017;17(1):109.1 